\title{
It's only a matter of time: flexibility, activities and time of use tariffs in the United Kingdom
}

Article

Accepted Version

Creative Commons: Attribution-Noncommercial-No Derivative Works 4.0

Torriti, J. and Yunusov, T. (2020) It's only a matter of time: flexibility, activities and time of use tariffs in the United Kingdom. Energy Research \& Social Science, 69. 101697. ISSN 2214-6296 doi:

https://doi.org/10.1016/j.erss.2020.101697 Available at https://centaur.reading.ac.uk/92146/

It is advisable to refer to the publisher's version if you intend to cite from the work. See Guidance on citing.

Published version at: http://dx.doi.org/10.1016/j.erss.2020.101697

To link to this article DOI: http://dx.doi.org/10.1016/j.erss.2020.101697

Publisher: Elsevier

All outputs in CentAUR are protected by Intellectual Property Rights law, including copyright law. Copyright and IPR is retained by the creators or other copyright holders. Terms and conditions for use of this material are defined in the End User Agreement.

www.reading.ac.uk/centaur 
Central Archive at the University of Reading

Reading's research outputs online 


\title{
It's only a matter of time: Flexibility, activities and Time of Use tariffs in the United Kingdom
}

\author{
Jacopo Torriti ${ }^{1}$, Timur Yunusov \\ School of the Built Environment, University of Reading, Whiteknights, PO Box 219, Reading, RG6 6AF, UK.
}

\begin{abstract}
In current academic, policy and industry debates there is significant emphasis on the importance of enhancing the level of flexibility of electricity demand. Flexibility is considered critical in order to improve balancing with renewables, reduce costs of electricity generation and make the most of smart systems and battery storage. There remain questions around how flexibility is delivered, and which portions of demand will take part in different aspects of flexibility markets. The aim of the paper is to identify activities in the home for which people may either gain or lose following the introduction of Time of Use (ToU) tariffs. It uses 2014-2015 UK Time Use Survey data to cluster households in terms of similarities in activities at peak time and identify households differently affected by ToU tariffs across several socio-demographic parameters (i.e. work status, income, family structure). Findings show that sociodemographic distribution did not demonstrate any significant dominant parameter. Instead, clustering based on similarities in the timing of activities has provided distinctive patterns and can shed light on groups of people who might be either advantaged or disadvantaged from the introduction of ToU tariffs.
\end{abstract}

\section{Keywords}

Demand; Electricity; Flexibility; Time of Use

\section{Introduction}

In current academic, policy and industry debates there is significant emphasis on the importance of enhancing the level of flexibility of electricity demand. Flexibility is considered critical in order to improve balancing with renewables, reduce costs of electricity generation and make the most of smart systems and battery storage. The monetary value of flexibility (that is the value of the potential to shift loads in time) plays an important role in explaining the market interest in this area and the expanding emphasis on the feasibility of different forms of intervention. For instance, the value of the technical potential of the flexibility market was estimated at around $f 8$ billion per year [1]. In this context, understanding how peaks are constituted, what demands are flexible, and what scope there is for effective load shifting becomes not only vital for the balancing of electricity demand and supply but also as a new form of market opportunity.

Provided that flexibility yields significant benefits for the balancing of the electricity grid and the reduction of system costs, there remain questions around how flexibility is delivered, and which portions of demand will take part in different aspects of flexibility markets. Historically, commercial and industrial end-users have been participating in demand side flexibility incentives through Demand Side Response programmes. In the future, it is expected that dynamic tariffs will be extended to significant portions of the residential sector. To this end, Time of Use (ToU) tariffs are expected to

\footnotetext{
${ }^{1}$ Corresponding author
} 
gradually replace flat tariffs and some provisions -for instance through the half hourly settlement reform in the UK [2]- have already been made in this regard. Previous studies pose questions regarding which effects these tariffs will have on residential consumers and who will be either advantaged or disadvantaged from such changes in pricing approaches. It is recognised in recent studies that the delivery of flexibility may vary across the population of residential consumers because the capital costs of flexibility may be unaffordable to some [3] Also, variations in how flexibility is delivered are due to different attributes of practices [4]. The starting point of this paper is that flexibility -through ToU tariffs- may affect residential electricity consumers differently depending on the timing of activities. Understanding how different socio-demographic groups may financially win or gain from the introduction of ToU tariffs depending on what they do at peak and off-peak times is a policy imperative which may shape regulation concerned with the distributional effects of flexibility. In addition to identifying socio-demographic groups (in terms of income and household composition) by estimating the peak to off-peak ratios of their energy-related activities, this paper will cluster households based on similarities in time use activities during peaks. This will shed light on the extent to which certain activities mostly take place at peak time and will be more negatively affected by ToU tariffs.

The aim of the paper is to identify activities in the home for which people may either gain or lose financially following the introduction of ToU tariffs. It uses 2014-2015 UK Time Use Survey data to cluster households by their energy-related activities during the peak electricity demand periods, cluster households in terms of similarities in activities at peak time and identify households differently affected by ToU tariffs across several socio-demographic parameters.

The paper reviews work which analysed the distributional effects of ToU tariffs, research on flexibility in terms of distributional effects of ToU tariffs, flexibility of practices and time use (Section 2). It describes the data utilised for the analysis as well as how clustering techniques, ToU tariffs and peak to off-peak ratios were developed (Section 3). Findings are presented in terms of household composition, income groups and clusters (Section 4). The paper concludes by discussing the implications and limitations of this study (Section 5).

\section{Time of Use tariffs: distributional effects and time use activities}

Time of Use tariffs are designed to mitigate peaks in electricity demand and enable demand-side flexibility. They are expected to reduce costs of the electricity system by preventing additional power generation and transmission capacity. The massive adoption of ToU tariffs in the residential sector as a form of implicit demand-side flexibility raises questions around both financial affordability and time availability based on people's activities. The means for shifting electricity demand are not equal across the population of residential users [5]. Two distinct positions in the literature demonstrate how residential capacity to respond to ToU tariffs may vary based on availability of income and time. First, the literature on energy justice interrogates how ToU will be afforded by different socio-demographic groups in terms of flexibility capital. Second, existing configurations in terms of time of activities bring about variations in how flexibility is delivered due to different attributes of practices. These two positions are explained below.

\subsection{Affording flexibility and distributional effects of Time of Use tariffs}

The disparities associated with affording flexibility and ToU tariffs can be framed as part of the literature on energy justice. Research in this context has often relied on ethical principles [6], which need to be reframed when discussing justice and flexibility of both systems [7] and demand [8]. The literature on energy justice has been expanding in recent years[9][10] and includes distributional issues [11] mainly applied to resources [12]. When applied to demand-side flexibility, research on 
energy justice has been associated with large portions of consumers being unable to own sufficient flexibility capital in order to benefit from real-time pricing [3]. This is because there are capital costs associated with accessing technologies which increase the volumes and hence levels of remuneration associated with flexibility services. These include home batteries, solar panels, electric vehicles and smart appliances.

Research on vulnerable consumers typically considers average energy consumption, whereas the distributional impacts of ToU remain largely unexplored. In this context, ToU effects are likely to vary for consumers with different socio-demographic profiles. Consumption during peak periods is penalised with peak tariffs. The combination of being unable to afford higher prices of electricity and a high ratio of electricity consumption during peak periods would generate a highly negative economic effect.

Changes in tariffs can trigger both positive and negative effects on different socio-demographic groups. Consumers' behavioural responses to ToU pricing were estimated as part of a study which attempted to assess bill-level effects of such tariffs [13]. There are consumers in all groups that would be disadvantaged because of ToU adoption tariffs albeit only marginally. The study's results show that most socio-demographic categories, apart from higher income groups, could on average be associated with lower bills thanks to the introduction of ToU. An earlier UK study points to limited financial effects for most socio-demographic groups. However, according to the same study some sociodemographic groups would see energy bill increases in the order of $20 \%$. With regards to specific lower-income groups and vulnerable consumers, there is a lack of studies investigating the relationship between ToU and distributional effects [14]. Furthermore, socio-demographic parameters and ToU tariffs do not generate a statistically significant relationship [15] [16] This can be partly attributed to the fact that the information collected on electricity consumption based on smart meter data does not provide much detail on socio-demographic parameters [17].

Higher volumes of demand across socio-demographic groups (mainly relating to household size) can help explain some of the effects in any change in tariffs. In addition to house type, house size, and house age, other socio-demographic characteristics such as age, income, education and household size are seldom taken into account in studies on the effects of ToU [18]. A Belgian study finds that age matters in the choice of flexible technologies [19]. Existing reviews of U.S. studies show that lower income groups feature lower savings peak reduction than other groups [20].

2.2 Flexibility of practices and time useThe extent to which residential demand can provide flexibility is related to time availability and people's activities. There is a growing literature studying flexibility in terms of time of activities and social practices. In this brief review, the emphasis is on two approaches in existing empirical studies which operationalise the timing of activities in relation to flexibility.

First, studies based on the flexible attributes of practices group energy-related practices according to the flexibility they can provide. For instance, lighting, heating and cooling of spaces belong to one group as they relate to comfort [21](Seasonality affects the daily rhythms of lighting and heating, which are otherwise highly inflexible. In [4] cooking, eating and leisure activities can be clustered together. Food and entertainment also play an important role in shaping and maintaining social bonds between members of a household. That makes the timing of food and entertainment practices a matter of (often complex) coordination between household members first. The grouping of activities through networks has also been used to infer flexibility [22]. Electricity intensive forms of entertainment like watching TV and video gaming are two more examples of inflexible practices during which people relax and are typically less reflexive of energy issues. Domestic cleaning represents a separate category of practices most commonly associated with running a household [4]. Domestic 
cleaning practices, such as laundering, are relatively flexible in time [23]. Smale et al. in [21] group practices in relation to appliances involved and issues around time the distinctions made above. This shows that timing is critical for lighting, heating and cooling spaces; cooking, eating and leisure activities are time critical, whereas domestic cleaning is not seen as time critical.

Second, studies focusing on the timing of energy demand shed light on flexibility based on when activities take place. Conceptualising flexibility as an outcome of sequencing and synchronisation of social practices means focusing on the social rhythms and the timing of what people do [24]. Flexibility can only be understood though more detailed and disaggregated insights into practices and energy rhythms [25]. This focus on the timing of practices is epitomised by time use research explaining what constitutes electricity demand at different periods of the day [26]. As an empirical approach, time use studies have developed occupancy models from time use data with a view to develop electricity demand profiles [27]-[29]. Historical time use survey data reveals evolving demand and traces of flexibility [30]. However, previous time use studies have not focused on which activities take place in correspondence with peak and off-peak ToU tariffs.

\section{Methodology}

The methodological approach of this paper comprises four main steps. First, time use activity data was processed to obtain socio-demographic information and derive energy related activities for each household. Second, households were clustered according to similarities in energy related activities during peak periods. Third, the main socio-demographic characteristics of every cluster were identified and examined. Fourth, for both clusters and socio-demographic approaches we derive peak to off-peak ratios with a view to identify which activities would be most advantaged or disadvantaged from ToU pricing.

\subsection{Data}

Activity and socio-demographic data were derived from the 2014-2015 UK Time Use Survey (UKTUS)[31], which consists of about 16,000 activities and represents a nationally representative source of information for time use activities. In addition to an activity dairy, the UKTUS includes a household survey with data on income of residents, their occupation, employment status, but also household structure and age of householders. Activities (based on 270 individual activity codes) and location were recorded with a time granularity of 10 minutes. We grouped activity codes in terms of their links with electricity demand. Since UKTUS provides data for up to four simultaneous activities, primary, secondary, tertiary and quaternary energy related activities of each household were added to derive a profile of activities. The energy related profiles were normalised. With regards to sociodemographic data, this consists of (i) number of children in the household; (ii) overall income of the household; (iii) respondents' age; (iv) respondents' employment status; (v) number of residents in full-time education; (vi) household type; (vii) number of rooms; and (viii) property type.

\subsection{Clustering}

For each household we clustered normalised weekday energy related activities applying the k-medoid method. This is based on the k-means clustering algorithm, where instead of the mean the centroid is selected in each cluster. Hence, we cluster by appraising the similarity across households of average energy related activities on weekdays between 4PM and 8PM. In practice, such similarity is calculated based on Euclidean distance between average energy related activities. The Euclidean distance means that the sum of differences between each profile and the medoid profile provides the clusters. The resulting number of clusters (i.e. 20) maintains a satisfactory cluster population size and enables an acceptable group variety in terms of number of energy related activities at different times of the day. 


\subsection{Tariffs and peak to off-peak ratio}

In order to decide which periods would count as peak and off-peak a brief review of ToU tariffs in the UK literature was carried out, mainly based on two studies authored by Hledik et al. [15]and the Centre for Sustainable Energy [32]. The timings and the tariff levels are illustrated in Figure 1. The focus of our analysis is on the timings.

The upper graph in Figure 1 shows ToU tariffs as defined in the study by the Centre for Sustainable Energy [32]. The first ToU represents a two-level tariff with peak time pricing applied every day from 4PM to 8PM. The second tariff consists of three prices with (i) daily peak time from 4PM to 8PM; (ii) middle prices between 7AM and 4PM and from 8PM to 11PM; and (iii) lower pricing applied at all other times of the day. The third tariff differs from the second one because the highest and middle price are only applied from Monday to Friday (and not applied to weekends). The lower graph in Figure 1 shows static ToU tariffs featuring in [15] consists of peak time pricing from 4PM to 8PM for every day of the week.
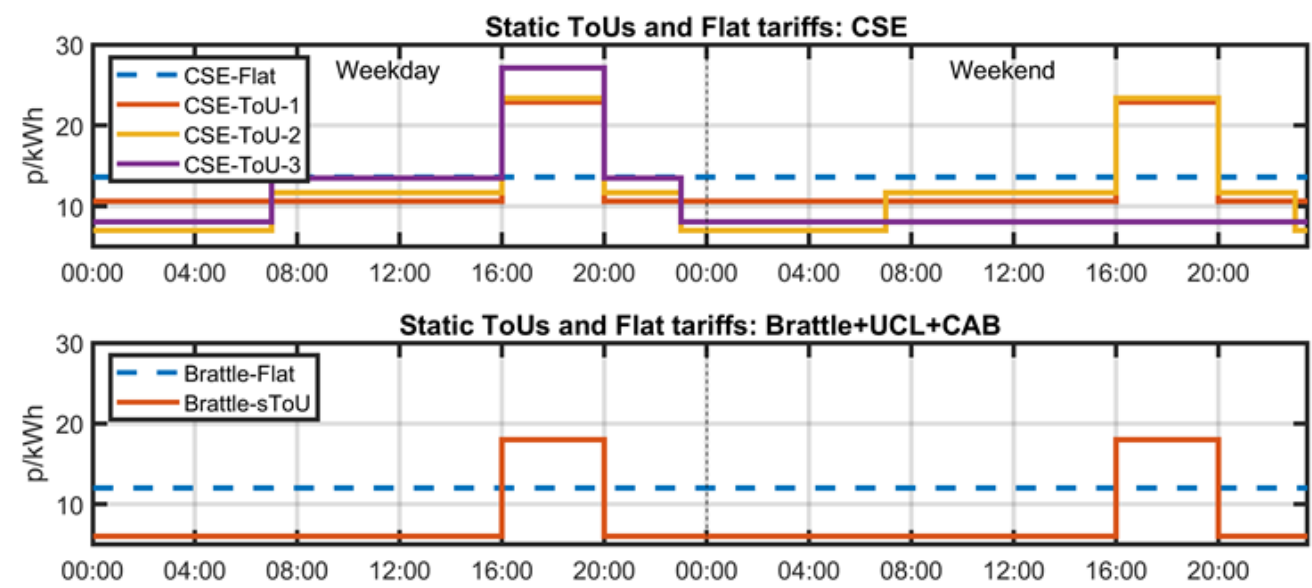

Figure 1: Pricing and timings associated with different ToU tariffs

The main emphasis of these studies as well as other work on the effects of ToU tariffs is on behavioural impacts and how this triggers changes in electricity demand. Conversely, our work assumes that behavioural change associated with ToU is negligible since the temporalities of everyday life carry on because of the predominance of work and social commitments irrespective of change to electricity tariffs [33]. Hence, for this analysis it was derived from this brief review that peak time pricing is applied daily (both weekday and weekend) between 4PM and 8PM.

The brief review of ToU tariffs enabled to separate peak periods (between 4PM and 8PM) from offpeak periods (from midnight to 4PM and from 8PM to midnight). Peak to off-peak ratios are calculated in 10-minute intervals to represent a high time granularity of which activities are penalised for happening at peak time and which activities are rewarded for happening off-peak.

\section{Analysis of time use data}

\subsection{Household composition}

Figure 2 illustrates the probability of active occupancy, cooking, laundry, TV watching and ironing taking place at different times of the day during weekdays for 11 type of family structures, broadly defined by number of adults (single or couple), number of children (none, one, more than two or with children over 16). With regards to active occupancy, this is higher for retired couples and Single retired persons during the day (off-peak) and lower for single persons and single parents ( 1 or more than two, 
but not with adult children). However, single households exhibit lowest occupancy during peak. The presence of children across all (including complex) households is associated with an increase in active occupancy in the period preceding peak time.

Households without children have lower levels of cooking around lunch time, but reach the highest levels of cooking in the evening, whereas retired couples have the most pronounced peaks in cooking activities around all three traditional mealtimes. Single parents have a high asymmetry during the day, with most cooking taking place in the evening. Retired couples are associated with the highest level of laundry during off-peak periods (especially in the weekday mornings), while households without children carry out high levels of laundry-related activity during evening peaks and single households are associated with very low laundry activity in the evenings.

Laundry activities are carried out more frequently during the day by households with retired couples and single parent households with two or more children. On the other hand, single parents with adult children and couples with two or more children are more likely than others to carry out laundry activity at the start of the peak time period. TV watching features a similar pattern for most of the households with a varying degree of intensity at the end of the peak-time period. The exceptions include retired couples and complex families, who tend to watch TV more during the day.
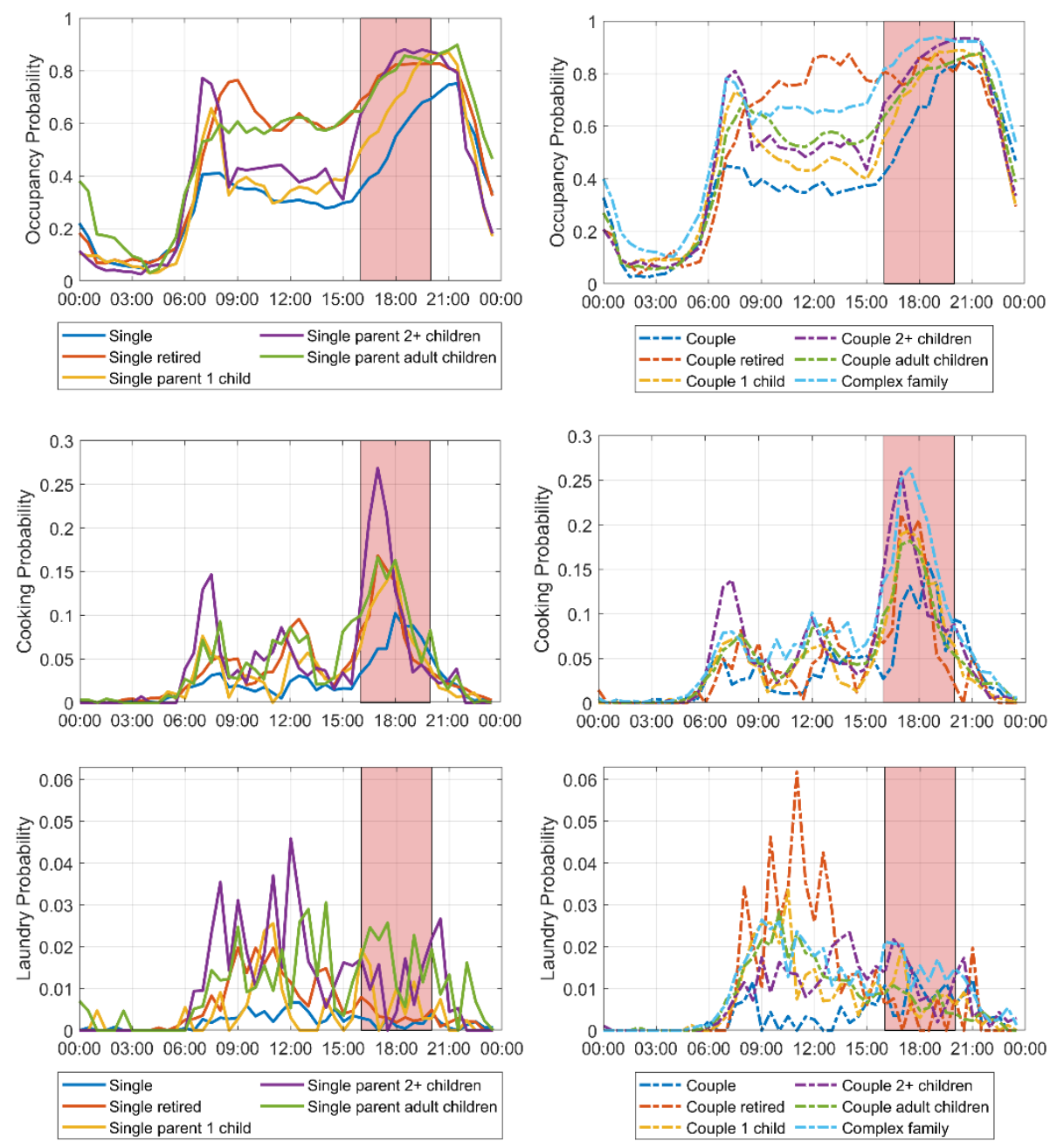

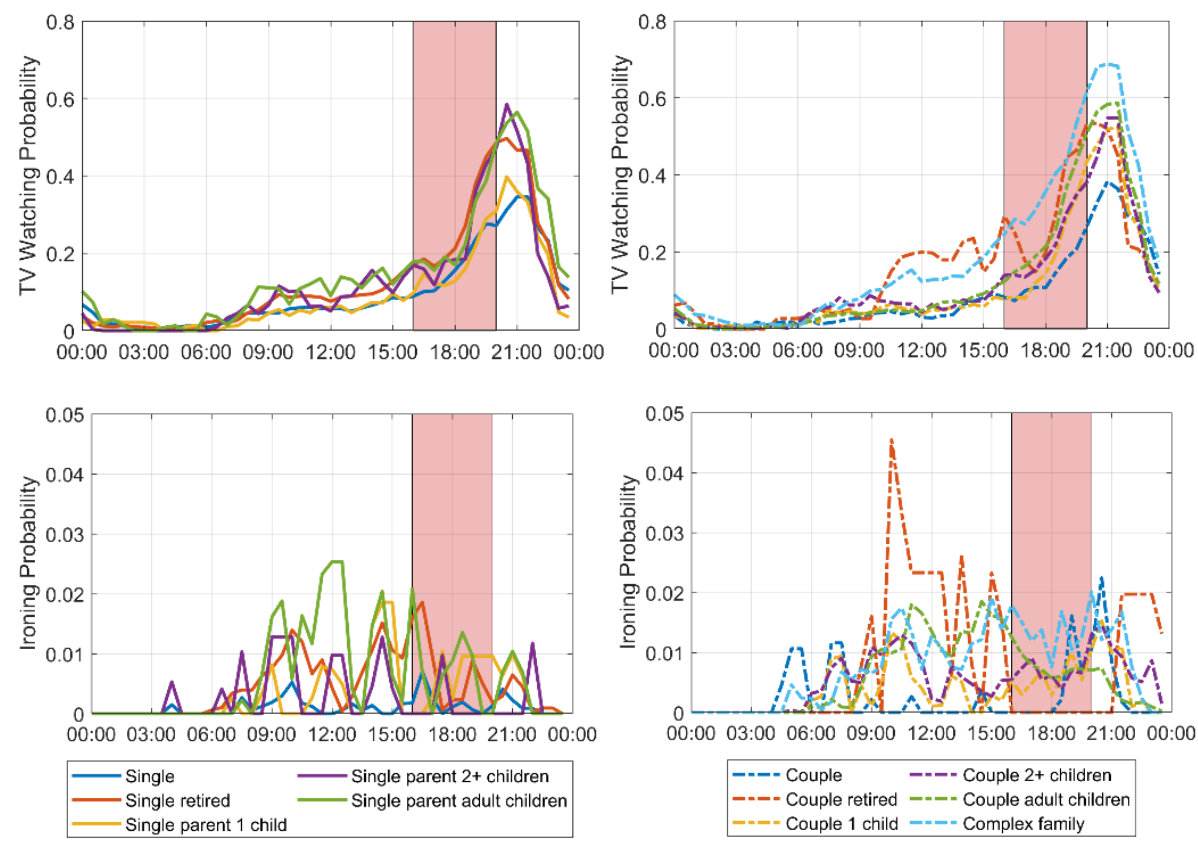

Figure 2: Probabilities by household composition associated with active occupancy, cooking, doing laundry, TV watching and ironing (weekdays).

Figure 3 provides a comparison of peak to off-peak ratios by household composition. Single parent households and households without children are four times more likely to cook a meal during the evening peak (i.e. between 4PM and 8PM) than during the rest of the day. Single households and retired couples are the only household composition categories with peak to off-peak ratios lower than one in relation to ironing and laundry. Active occupancy presents peak to off-peak ratios which are very similar across all household composition categories.

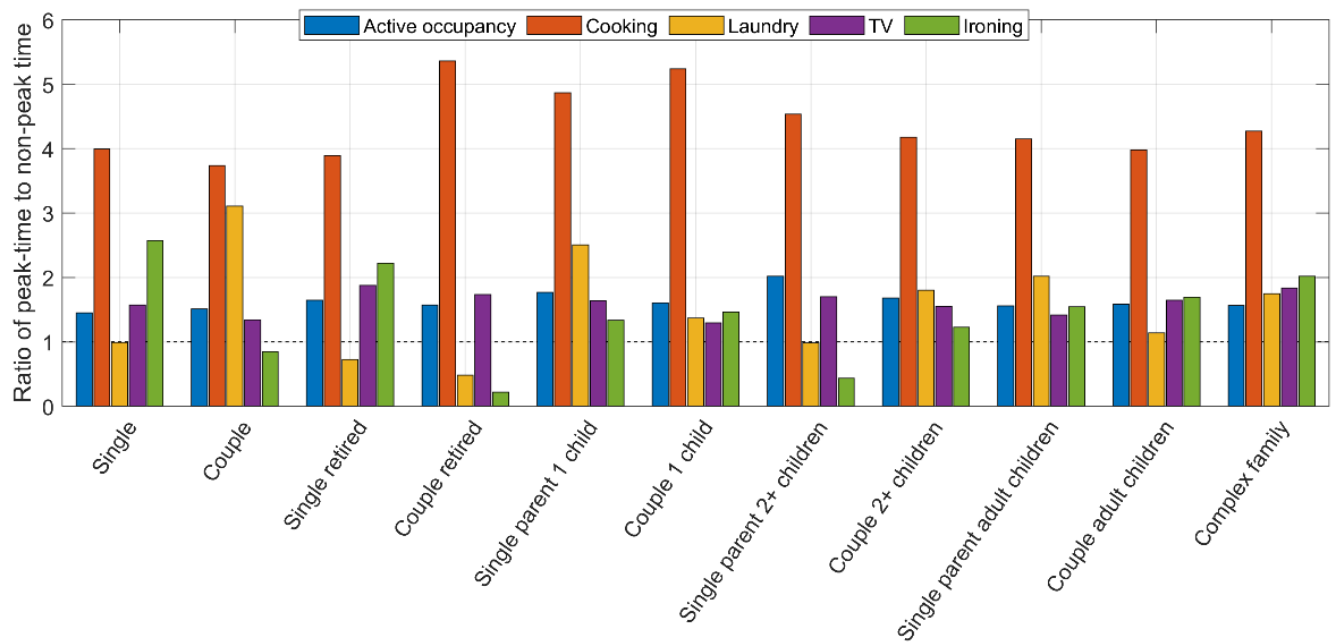

Figure 3: Comparison of peak to off-peak ratios by household composition (active occupancy, cooking, laundry, TV and ironing)

\subsection{Income groups}

The UKTUS respondents were organised into six income groups to ensure different income ranges and percentiles of UK income distribution are represented in the analysis. Table 1 shows the percentile of UK income distribution and ranges of the income groups. 


\begin{tabular}{|c|c|c|}
\hline Group & $\begin{array}{c}\text { Percentile of UK income } \\
\text { distribution }\end{array}$ & Range in fk \\
\hline Low income & Bottom $20 \%$ & $<19$ \\
\hline Lower middle income & $20^{\text {th }}-41^{\text {st }}$ percentile & 26 \\
\hline Middle income & $42^{\text {nd }}-60^{\text {th }}$ percentile & $36-49$ \\
\hline Upper middle income & $61^{\text {st }}-80^{\text {th }}$ percentile & $49-60$ \\
\hline High income & $80^{\text {th }}-90^{\text {th }}$ percentile & $>60$ \\
\hline Very high income & Top $10 \%$ & \\
\hline
\end{tabular}

Table 1: Income groups, percentile of UK income distribution and ranges

Figure 4 shows how active occupancy, cooking and laundry vary by time of the day for three different income groups during weekdays. During the day, the probability of active occupancy is on average higher for the low-income group and lower for the high-income group and the same position holds at the beginning of the evening peak (pink area in the graphs). However, as the evening progresses and active occupancy reaches the highest probability level of the entire day (above $80 \%$ ), there is no distinction across income groups. The high-income group overtakes the other two income groups after 8PM (i.e. during the off-peak period). The activity of cooking is distinguished by the three meal periods with lower levels for the low-income group and higher levels for the middle-income group during the evening hours. The laundry activity features a significantly high probability for the low-income group during the morning.
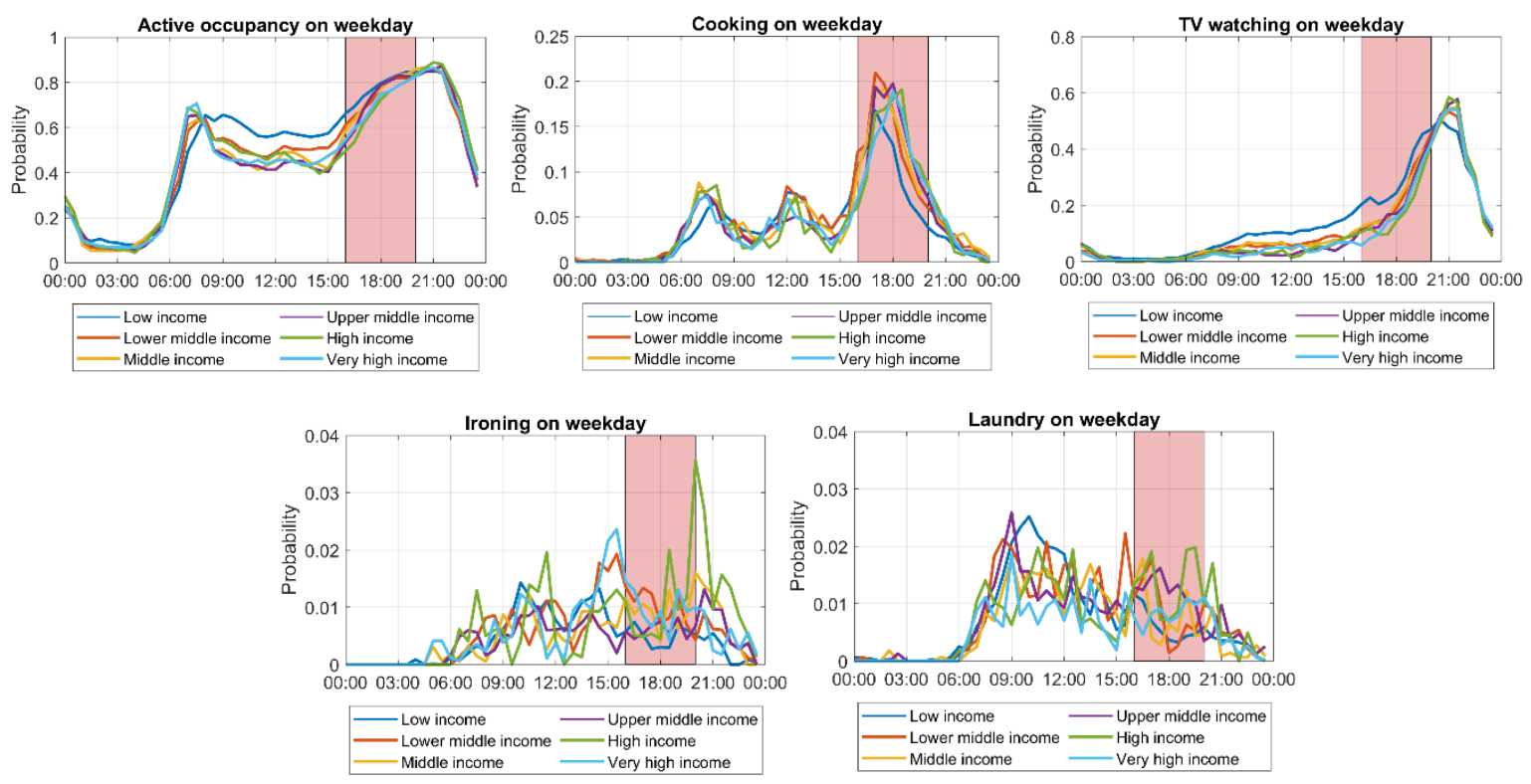

Figure 4: Probabilities by income associated with active occupancy, cooking, laundry, ironing and TV watching (weekdays)

Figure 5 compares peak and off-peak ratios of active occupancy, cooking, laundry, TV and ironing by income groups. Peak to off-peak ratios lower than 1 (such as laundry and ironing for the low-income group) consist of activities taking place mostly off-peak. The graph shows how most activities for all income groups are most likely to take place during peak time as their peak to off-peak ratio is higher than 1. For instance, active occupancy has a very similar peak to off-peak ratio across all income 
groups. Cooking is associated with the highest peak to off-peak ratio due to the dominant synchronisation of dinners, with high income groups experiencing the maximum ratio.

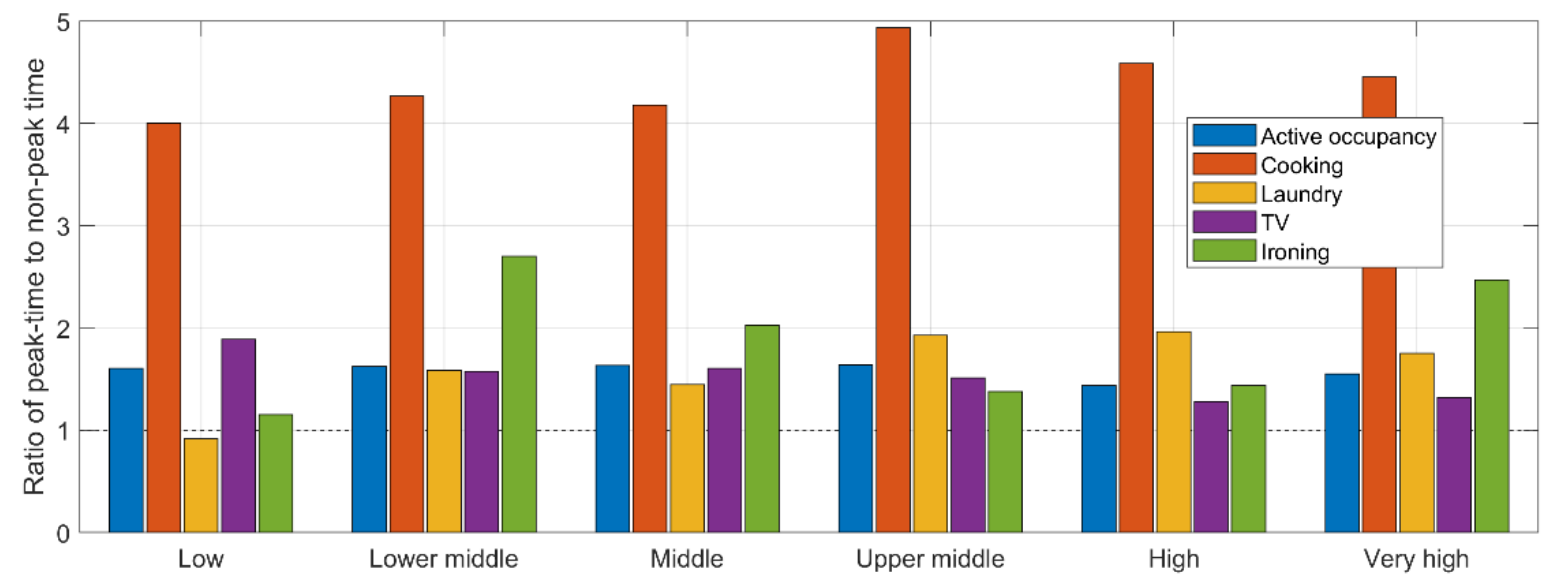

Figure 5: Comparison of peak to off-peak ratios by income (active occupancy, cooking, laundry, TV and ironing)

\subsection{Clusters}

Households were clustered on the basis of similarities of activities during evening peaks. Figure 2 shows the mean and standard deviation of energy related activities for the 20 clusters. The overall trends in energy related activities resemble household electricity load profiles, with activities being increasingly reduced after midnight morning peaks starting at about 7AM and the highest levels during the evening peak, which is represented by the red area in Figure 6.

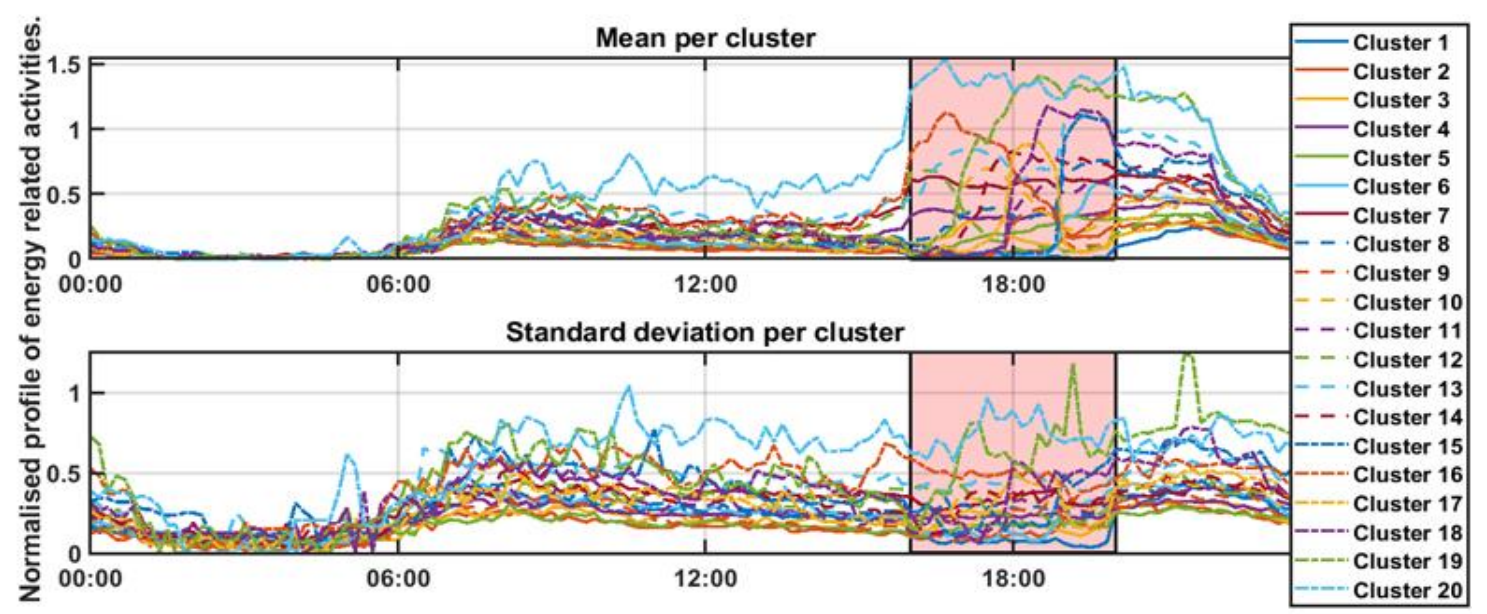

Figure 6: Clusters' mean and standard deviations of energy related activities

For the majority of clusters evening peaks involve higher energy related activities which start to decrease after 10PM. During periods of peak, the standard deviation is supposed to decline because of the type of clustering implemented in our paper. With the exception of cluster 20, standard deviations present relatively constant levels during the day and are mostly high including during the evening peak. Some clusters feature very distinct characteristics. For instance, cluster 20 presents a significantly distinct profile, with a higher number of energy related activities during the day compared with other clusters, which generally range between 0.2 and 0.3 . 


\begin{tabular}{|c|c|c|c|c|c|c|c|c|c|c|c|}
\hline Cluster \# & $\begin{array}{l}\frac{0}{600} \\
i=\end{array}$ & $\begin{array}{l}\frac{0}{0} \\
\frac{0}{3} \\
0\end{array}$ & 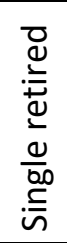 & 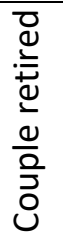 &  & 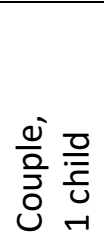 &  & 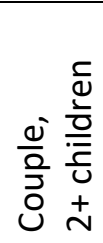 & 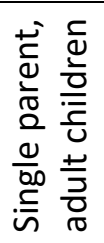 & 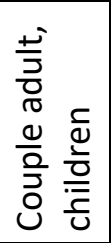 & 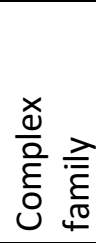 \\
\hline 0 & 11 & 1 & 13 & 1 & 2 & 5 & 1 & 10 & 3 & 26 & 13 \\
\hline 1 & 16 & 1 & 21 & 1 & 3 & 5 & 2 & 12 & 2 & 22 & 11 \\
\hline 2 & 5 & 1 & 5 & 0 & 4 & 5 & 3 & 28 & 2 & 26 & 16 \\
\hline 3 & 7 & 1 & 7 & 1 & 2 & 7 & 3 & 17 & 2 & 30 & 19 \\
\hline 4 & 4 & 1 & 4 & 0 & 4 & 9 & 2 & 16 & 3 & 31 & 24 \\
\hline 5 & 1 & 1 & 2 & 0 & 2 & 10 & 3 & 21 & 2 & 29 & 24 \\
\hline 6 & 15 & 2 & 18 & 1 & 6 & 5 & 2 & 4 & 2 & 34 & 10 \\
\hline 7 & 10 & 2 & 13 & 2 & 2 & 4 & 1 & 7 & 2 & 35 & 18 \\
\hline 8 & 9 & 2 & 11 & 1 & 3 & 6 & 1 & 12 & 4 & 28 & 22 \\
\hline 9 & 11 & 2 & 15 & 1 & 4 & 10 & 2 & 12 & 1 & 27 & 15 \\
\hline 10 & 10 & 1 & 18 & 1 & 1 & 5 & 1 & 7 & 4 & 34 & 16 \\
\hline 11 & 10 & 3 & 13 & 1 & 1 & 10 & 0 & 7 & 7 & 35 & 13 \\
\hline 12 & 15 & 1 & 31 & 1 & 1 & 1 & 0 & 5 & 3 & 31 & 9 \\
\hline 13 & 18 & 2 & 15 & 0 & 1 & 3 & 0 & 2 & 5 & 34 & 17 \\
\hline 14 & 20 & 2 & 16 & 1 & 2 & 4 & 0 & 2 & 7 & 30 & 15 \\
\hline 15 & 17 & 1 & 35 & 2 & 0 & 3 & 0 & 0 & 4 & 31 & 6 \\
\hline 16 & 23 & 7 & 22 & 2 & 1 & 3 & 0 & 1 & 2 & 31 & 11 \\
\hline 17 & 20 & 5 & 24 & 2 & 3 & 0 & 0 & 1 & 3 & 30 & 8 \\
\hline 18 & 32 & 1 & 21 & 0 & 0 & 1 & 0 & 0 & 2 & 30 & 12 \\
\hline 19 & 25 & 2 & 29 & 0 & 0 & 2 & 0 & 3 & 3 & 20 & 15 \\
\hline 20 & 23 & 2 & 25 & 2 & 0 & 2 & 0 & 0 & 3 & 33 & 7 \\
\hline
\end{tabular}

Table 1: Household composition percentage in each cluster

Table 1 shows percentages in terms of household composition in each cluster. These consist of single and couple variants of adults, retired adults and families with children (single child, more than two children and children over 16), and complex households. The heatmap colours are arranged across each type of household composition. Cluster 0 represents the entire survey sample. Most of the clusters have a strong presence of 'couple with children over 16, ranging from 26-35\%, with exception of cluster $19(20 \%)$ and cluster $1(22 \%)$. Single retired person households are predominant in clusters $15(35 \%)$ and $19(29 \%)$, whist single non-retired households have strongest representation in clusters 18 (32\%), 19 (25\%) and 20 (23\%). In the context of larger families, couples with more than two children have the strongest presence in cluster $2(22 \%)$ and complex families are mainly in clusters 4 and 5 (24\% each).

Figure 7 shows the peak to off-peak ratios of active occupancy, cooking, laundry, TV watching and ironing activities for the twenty clusters identified in terms of timing of peak activities in Section 4.1. Cooking reaches the highest peak to off-peak ratio for cluster 15 , whose households are five times more likely to carry out cooking during peak periods than during the rest of the day. Cooking has significantly high peak to off-peak ratios also in relation to clusters 3 and 17. For all clusters cooking and watching TV happens mostly during the evening peak. Laundry and ironing activities are more variable across clusters, with instances in which they are more likely to take place off-peak than during 
peaks (e.g. for clusters 7, 15 and 20) and others in which they are approximately as likely to take place off-peak as during peaks (e.g. for clusters $4,8,12,13$ ).

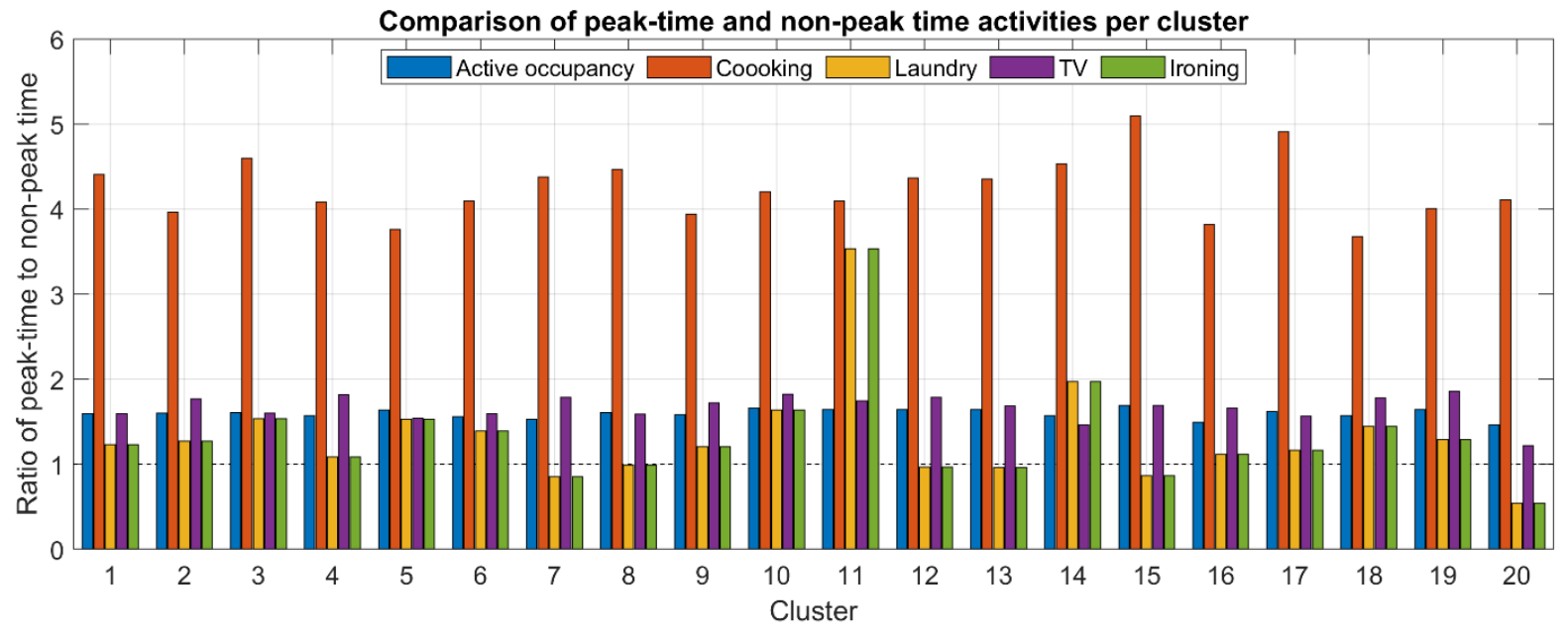

Figure 7: Comparison of peak to off-peak ratios by cluster (cooking, laundry and ironing)

The upper graph in Figure 8 shows the peak to off-peak ratios off all clusters for all energy-related activities. In the same figure, the graphs below show the distribution of the socio-demographic parameters in terms of cluster composition. It is therefore possible to compare not only clusters in terms of their peak to off-peak ratios, but also the income group, age, number of residents, employment status and number of rooms ${ }^{2}$ of each cluster. Cluster 11 experiences the highest peak to off-peak ratio and, consequently, is likely to face the highest losses following the introduction of ToU tariffs.

The socio-demographic description of cluster 11 does not present any outstanding features. These are households with low to middle income, middle-aged with two residents living in homes with four or five rooms. It is unsurprising that households losing out the most from their activities at peak time are concentrated in one cluster as the rationale for clustering based on similarity of activities at peak time was designed to identify groups of people who might be either advantaged or disadvantaged from higher tariffs at peak time. Despite having similar composition, cluster 7 is on the opposite spectrum. Clusters 3, 10 and 14 are also associated with high peak to off-peak ration and would lose out financially from ToU tariffs. With regards to the socio-demographic parameters, cluster 3 consists of relatively larger households, with 3 or more residents and significantly higher income. All other clusters have lower peak to off-peak ratios and would gain from ToU tariffs. Cluster 20 is associated with the lowest peak to off-peak ratio and would gain the most from tariffs charging more between $4 \mathrm{PM}$ and $8 \mathrm{PM}$. It is the cluster with, the lowest number of rooms, almost no children, mainly single residents, older than residents in cluster 11 and relatively low income.

\footnotetext{
${ }^{2}$ In UKTUS, define as number of household uses for private purposes (excluding bathrooms and toilets).
} 

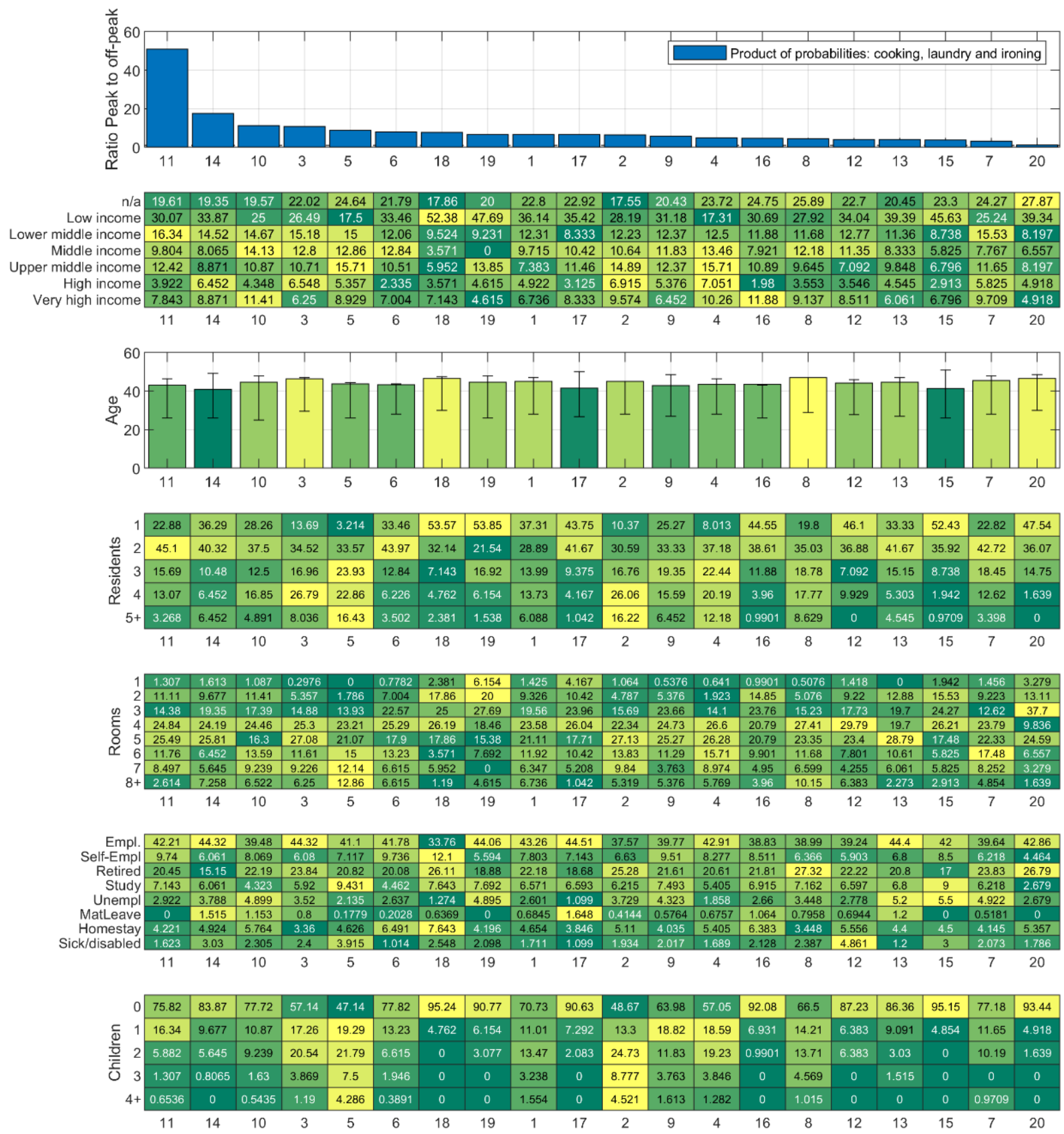

Figure 8: Comparison of peak to off-peak ratios by cluster and distribution of socio-demographic parameters for cluster composition (income group, age, number of residents, number of rooms, employment status and number of children). Clusters and corresponding socio-demographic information in descending order of product of peak to off-peak ratios of energy intensive activities.

\section{Conclusion}

Economic framings of ToU tariffs focus on measuring their effectiveness in inducing behavioural change and temporarily shifting consumption through price differentiation. According to these framings, consumers' ability and motivation to change consumption based on price signals varies according to income availability [34]. The extent to which this holds in different contexts has been challenged by studies in which own price elasticities show that the residential electricity demand during peak and off-peak periods is inelastic [35] and ToU did not generate the expected impacts [36]. Other framings posit that people's everyday lives and the rhythms of social practices may or may not always align with ToU tariffs [37] and the alignment may depend on interactions among household 
members [38] and different uptakes of smart homes [39]. Moreover, the non-alignment of these intersections raises energy justice issues in relation to the affordability of tariffs [40]. The emphasis of our work is to analyse impacts of ToU tariffs in relation not only to socio-demographics but also time of activities. These were analysed by socio-demographic groups (household type and income) and clusters based on similarities in time use activities during peaks.

The sociodemographic characteristics in each cluster do not point to any significant dominant parameter being able to explain the shape or intensity of energy-related activities during peak periods. This means that income and household structure, for instance, are not as powerful as activity-based clusters in describing changes in demand across the day because regardless of socio-demographic parameters different households might carry out very similar activities at peak time, experience the same peak to off-peak ratios and consequently face equivalent financial losses or gains due to the introduction of ToU tariffs. The activity-based clusters feature distinctive patterns in density and timing of energy-related activities in the morning. Clustering by activities represents a powerful way to appraise groups of people who might be either advantaged or disadvantaged from the introduction of ToU tariffs. This has conceptual implications for framing flexibility and its effects. Approaches which do not take as starting points either the socio-demographics of consumers or the flexible attributes of practices are better suited for understanding the complexities of demand-side flexibility. Instead, the results on clustering of activities at peak time suggest that the effects of ToU are better understood through analytical efforts to place time at the centre of research on flexibility. Both approaches place practices at the centre of research on flexibility. The main advantage of inferring flexibility through the attributes of practices consists of being able to directly assume what can be flexed. However, assumptions around the flexibility of practices risk being void of their temporal arrangements. Research on the effects of ToU tariffs cannot depart from issues of time, the timing of activities and their variation.

The findings of this paper trigger three main reflections.

First, for all clusters cooking happens mostly during the evening peak. This confirms the predominance of longer food preparation in connection with dinners compared with other meals [41]. This phenomenon is more pronounced in British society than in some other countries. For example, work comparing time use data from the UK and Germany points that the latter country experiences on average a higher level of cooking for lunch and a lower level in this activity for dinner [42]. This could be explained as part of a stronger tradition for cold meals for dinner in Germany compared (and vice versa) compared with the UK. Other clustering work shows the significance of dinner activities in explaining evening peaks as the strongest link consists of food preparation in relation to meal-time activities, especially cooking with energy-intensive appliances and eating hot meals [43].

Second, an eventual high electrification of cooking is likely to penalise particularly households with single parents as these are four times more likely to cook during the peak period than at any other point in the day. Parenting routines, school and childcare times and work times can create a 'time squeeze' in the mornings and evenings for working sole parents [44]. While eating in the UK has shifted to later in the evening over the last four decades [45]; [46], and its duration in the UK, USA, Norway and the Netherlands has been reduced over time [47] it seems unlikely that time of day pricing strategies will alter its temporality. With regards to occupancy, cooking and laundry, our paper shows large differences in the high peak to off peak ratios between single parents with children and the lower ratios associated with singles without children. This is consistent with concerns over the inflexibility and inability to respond to price signals of households with children [48]. In principle peak to off-peak ratios related to occupancy could be used as proxies for ToU effects of heating and (to some extent) charging of electric vehicles. 
Third, consumers who are locked-in because of scarce time availability and lower income might not be able to reap the benefits of ToU pricing approach. As a simple example, a single mother who works as a nurse, may have long shifts at the hospital and is not only on a low income, but also time scarce. She may happen to be at home and run household chores (washing machine, cooking combined with lighting, heating, etc.) at a time of the day which coincides with peak electricity demand. How do we identify this category of end-user? Moving beyond smart meter data or income-only data (for instance excluding low-income groups from ToU tariffs could be a mistake as some may gain from shifting demand, for instance if they stay at home for long periods) analysing data about what people do is the approach suggested in this paper. Clustering work such as the one presented in this paper is useful in order to facilitate the identification of households subject to ToU tariffs. This can be helpful both in terms of retailers' segmentation of their customers as well as for policy-makers designing exceptions as part of large rollouts of these types of tariffs (including tariffs based on actual capacity, tariffs based on agreed capacity, real-time pricing, critical peak pricing, critical peak rebates and block pricing). Policy makers will also be faced with challenging questions around either including or excluding vulnerable consumers from this new generation of tariffs. With the example of the single mother nurse, will protecting her from flexibility costs be feasible; will a higher level of protection involve excluding her from flexibility opportunities and the financial gains these bring about?

In terms of limitations, this paper assumes that people carry on with their everyday life irrespective of changes in tariffs. This is at odds with some the energy economics literature on price elasticity of energy demand, according to which people respond to changes in price through behavioural change depending on their income [49], but conforms with the view that people do not have preferences when it comes to energy demand as this is a matter of negotiating the rhythms of practices and material arrangements [50]. This is consistent with findings from other studies which suggest that the most important variable when it comes to reacting to price is how any change can be accommodated within the domain of everyday life [51]. In taking an innovative approach on activities, ToU tariffs and the timing of electricity demand, this work contributes to a better understanding of these issues taken together.

\section{Research Grants}

This work was supported by UKRI, grant numbers EP/R000735/1, EP/R035288/1 and EP/P000630/1.

\section{References}

[1] National Infrastructure Commission, "Smart Power," 2016.

[2] Ofgem, "Consultation on mandatory half-hourly settlement: aims and timetable for reform," London, 2016.

[3] G. Powells and M. J. Fell, "Flexibility capital and flexibility justice in smart energy systems," Energy Research and Social Science, vol. 54. pp. 56-59, 2019.

[4] F. Friis and T. Haunstrup Christensen, "The challenge of time shifting energy demand practices: Insights from Denmark," Energy Res. Soc. Sci., vol. 19, pp. 124-133, 2016.

[5] J. Torriti, R. Hanna, B. Anderson, G. Yeboah, and A. Druckman, "Peak residential electricity demand and social practices: Deriving flexibility and greenhouse gas intensities from time use and locational data," Indoor Built Environ., vol. 24, no. 7, pp. 891-912, 2015.

[6] B. K. Sovacool and M. H. Dworkin, "Energy justice: Conceptual insights and practical applications," Appl. Energy, vol. 142, pp. 435-444, 2015.

[7] G. Thomas, C. Demski, and N. Pidgeon, "Energy justice discourses in citizen deliberations on 
systems flexibility in the United Kingdom: Vulnerability, compensation and empowerment," Energy Res. Soc. Sci., vol. 66, 2020.

[8] G. Walker, N. Simcock, and R. Day, "Necessary energy uses and a minimum standard of living in the United Kingdom: Energy justice or escalating expectations?," Energy Res. Soc. Sci., vol. 18, pp. 129-138, 2016.

[9] K. Jenkins, D. McCauley, and A. Forman, "Energy justice: A policy approach," Energy Policy, vol. 105. pp. 631-634, 2017.

[10] K. Bickerstaff, G. Walker, and H. Bulkeley, Energy justice in a changing climate: social equity and low-carbon energy. Zed Books Ltd, 2013.

[11] K. Jenkins, D. McCauley, R. Heffron, H. Stephan, and R. Rehner, "Energy justice: A conceptual review," Energy Research and Social Science, vol. 11. pp. 174-182, 2016.

[12] G. Walker, "Beyond distribution and proximity: Exploring the multiple spatialities of environmental justice," in Antipode, 2009, vol. 41, no. 4, pp. 614-636.

[13] Cambridge Economic Policy Associates, "Distributional impact of time of use tariffs," 2017.

[14] Frontier Economics and Sustainability First, "Domestic and SME tariff development for the Customer - Led Network Revolution," 2012.

[15] R. Hledik, W. Gorman, N. Irwin, M. Fell, M. Nicolson, and G. Huebner, "The Value of TOU Tariffs in Great Britain : Insights for Decision-makers," vol. I, no. July, pp. 1-63, 2017.

[16] M. Nicolson, G. Huebner, and D. Shipworth, "Are consumers willing to switch to smart time of use electricity tariffs? The importance of loss-aversion and electric vehicle ownership," Energy Res. Soc. Sci., vol. 23, pp. 82-96, 2017.

[17] R. Ozaki, "Follow the price signal: People's willingness to shift household practices in a dynamic time-of-use tariff trial in the United Kingdom," Energy Res. Soc. Sci., vol. 46, pp. 10-18, 2018.

[18] J. Stromback, C. Dromacque, and M. Yassin, "The potential of smart meter enabled programs to increase energy and systems efficiency: a mass pilot comparisonShort name: Empower Demand," 2011.

[19] A. Srivastava, S. Van Passel, and E. Laes, "Dissecting demand response: A quantile analysis of flexibility, household attitudes, and demographics," Energy Res. Soc. Sci., vol. 52, pp. 169-180, 2019.

[20] A. Faruqui and S. Sergici, "Arcturus: International Evidence on Dynamic Pricing," SSRN Electron. J., vol. 26, no. 7, pp. 55-65, 2013.

[21] R. Smale, B. van Vliet, and G. Spaargaren, "When social practices meet smart grids: Flexibility, grid management, and domestic consumption in The Netherlands," Energy Res. Soc. Sci., vol. 34, no. June, pp. 132-140, 2017.

[22] E. McKenna, S. Higginson, T. Hargreaves, J. Chilvers, and M. Thomson, "When activities connect: Sequencing, network analysis, and energy demand modelling in the United Kingdom," Energy Res. Soc. Sci., vol. 69, 2020.

[23] T. Jack, "Cleanliness and consumption: exploring material and social structuring of domestic cleaning practices," Int. J. Consum. Stud., vol. 41, no. 1, pp. 70-78, Jan. 2017.

[24] S. Blue, E. Shove, and P. Forman, "Conceptualising flexibility: Challenging representations of time and society in the energy sector," Time Soc., 2020. 
[25] G. Walker, "The dynamics of energy demand: Change, rhythm and synchronicity," Energy Res. Soc. Sci., vol. 1, pp. 49-55, 2014.

[26] J. Torriti, "A review of time use models of residential electricity demand," Renew. Sustain. Energy Rev., vol. 37, pp. 265-272, 2014.

[27] E. McKenna and M. Thomson, "High-resolution stochastic integrated thermal-electrical domestic demand model," Appl. Energy, vol. 165, pp. 445-461, 2016.

[28] I. Richardson, M. Thomson, and D. Infield, "A high-resolution domestic building occupancy model for energy demand simulations," Energy Build., vol. 40, no. 8, pp. 1560-1566, 2008.

[29] I. Richardson, M. Thomson, D. Infield, and C. Clifford, "Domestic electricity use: A highresolution energy demand model," Energy Build., vol. 42, no. 10, pp. 1878-1887, 2010.

[30] B. Anderson, "Laundry, energy and time: Insights from 20 years of time-use diary data in the United Kingdom," Energy Res. Soc. Sci., vol. 22, pp. 125-136, 2016.

[31] J. Gershuny and O. Sullivan, United Kingdom Time Use Survey, 2014-2015. [data collection]. SN: 8128. UK Data Service, 2017.

[32] Centre for Sustainable Energy, "Investigating the potential impacts of Time of Use (TOU) tariffs on domestic electricity customers Report to Ofgem," 2014.

[33] J. Torriti, "Understanding the timing of energy demand through time use data: Time of the day dependence of social practices," Energy Res. Soc. Sci., vol. 25, pp. 37-47, 2017.

[34] S. M. Baladi, J. A. Herriges, and T. J. Sweeney, "Residential response to voluntary time-of-use electricity rates," Resour. Energy Econ., vol. 20, no. 3, pp. 225-244, 1998.

[35] M. Filippini, "Short- and long-run time-of-use price elasticities in Swiss residential electricity demand," Energy Policy, vol. 39, no. 10, pp. 5811-5817, 2011.

[36] J. Torriti, "Price-based demand side management: Assessing the impacts of time-of-use tariffs on residential electricity demand and peak shifting in Northern Italy," Energy, vol. 44, no. 1, pp. 576-583, 2012.

[37] Y. Strengers, "Peak electricity demand and social practice theories: Reframing the role of change agents in the energy sector," Energy Policy, vol. 44, pp. 226-234, 2012.

[38] S. Bell, E. Judson, H. Bulkeley, G. Powells, K. A. Capova, and D. Lynch, "Sociality and electricity in the United Kingdom: The influence of household dynamics on everyday consumption," Energy Res. Soc. Sci., vol. 9, pp. 98-106, 2015.

[39] C. Wilson, T. Hargreaves, and R. Hauxwell-Baldwin, "Benefits and risks of smart home technologies," Energy Policy, vol. 103, pp. 72-83, 2017.

[40] L. Middlemiss and R. Gillard, "Fuel poverty from the bottom-up: Characterising household energy vulnerability through the lived experience of the fuel poor," Energy Res. Soc. Sci., vol. 6, pp. 146-154, 2015.

[41] J. L. Ramírez-Mendiola, P. Grünewald, and N. Eyre, "The diversity of residential electricity demand - A comparative analysis of metered and simulated data," Energy Build., vol. 151, pp. 121-131, 2017.

[42] R. Mckenna, M. Kleinebrahm, T. Yunusov, M. J. Lorincz, and J. Torriti, "Exploring socioeconomic and temporal characteristics of British and German residential energy demand," in British Institute of Energy Economi, 2018, pp. 1-14. 
[43] A. Satre-Meloy, M. Diakonova, and P. Grünewald, "Cluster analysis and prediction of residential peak demand profiles using occupant activity data," Appl. Energy, vol. 260, 2020.

[44] D. Nockolds, "Acceleration for working sole parents: Squeezed between institutional temporalities and routinised parenting practices," Time Soc., vol. 25, no. 3, pp. 513-532, 2016.

[45] B. Anderson and J. Torriti, "Explaining shifts in UK electricity demand using time use data from 1974 to 2014," Energy Policy, vol. 123, pp. 544-557, 2018.

[46] M. Durand-Daubin and B. Anderson, "Changing eating practices in france and great britain: Evidence from time-use data and implications for direct energy demand," in Demanding Energy: Space, Time and Change, 2017, pp. 205-231.

[47] A. Warde, S. L. Cheng, W. Olsen, and D. Southerton, "Changes in the practice of eating: A comparative analysis of time-use," Acta Sociol., vol. 50, no. 4, pp. 363-385, 2007.

[48] L. Nicholls and Y. Strengers, "Peak demand and the 'family peak' period in Australia: Understanding practice (in)flexibility in households with children," Energy Res. Soc. Sci., vol. 9, pp. 116-124, 2015.

[49] J. I. Silk and F. L. Joutz, "Short and long-run elasticities in US residential electricity demand: A co-integration approach," Energy Econ., vol. 19, no. 4, pp. 493-513, 1997.

[50] E. Shove and G. Walker, "What Is Energy For? Social Practice and Energy Demand," Theory, Cult. Soc., vol. 31, no. 5, pp. 41-58, 2014.

[51] S. Buryk, D. Mead, S. Mourato, and J. Torriti, "Investigating preferences for dynamic electricity tariffs: The effect of environmental and system benefit disclosure," Energy Policy, vol. 80, pp. 190-195, 2015. 